\title{
Ideal position and size selection of unified power flow controllers (UPFCs) to upgrade the dynamic stability of systems: An antlion optimiser and invasive weed optimisation algorithm
}

\author{
Mythili Shanmugam ${ }^{1}$, Thiyagarajah $\mathrm{K}^{2}$, Paulthurai Rajesh ${ }^{3}$ and Francis H Shajin ${ }^{3}$ \\ ${ }^{1}$ Electrical and Electronics Engineering Department, Mahendra College of Engineering for Women, Namakal, India \\ ${ }^{2}$ K.S.Rangasamy College of Technology, Namakkal, India \\ ${ }^{3}$ Anna University, Chennai, India
}

\begin{abstract}
This paper proposes a hybrid methodology to improve the dynamic strength of frameworks by optimally locating and sizing the unified power flow controller (UPFC). The proposed method combines both the antlion optimiser (ALO) and invasive weed optimisation (IWO) techniques. The advantages of the proposed methodology are enhanced searching ability, better identification of optimal solutions and greater reliability. Initially, to locate UPFCs, using the ALO technique, the most extreme power loss bus is recognised as the optimal location. The capacity required to resolve the situation is determined by the IWO technique based on the minimum power loss, voltage deviation and establishment cost of the UPFCs. The proposed system is actualised and aims at the matrix laboratory (MATLAB) environment, while the power flow security and voltage stability are evaluated on the basis of the Institute of Electrical and Electronics Engineers (IEEE) standard benchmark system. At this point, voltage stability, power loss, overloading and UPFC costs are analysed through changing the system load and generation. The proposed working method is then assessed and compared with traditional techniques.
\end{abstract}

KEYWORDS Particle swarm optimisation (PSO); invasive weed optimisation (IWO); antlion optimiser (ALO); power loss; unified power flow controllers (UPFCs)

CONTACT Mythili Shanmugam mythili0519@gmail.com

Received on 24 March 2018

\section{Introduction}

With a continuously growing demand for electricity, power generating companies are looking at not only new power plants but also renewable energy sources to meet current needs. As power is often generated far from where it is needed, especially with renewable energy, robust transmission networks must therefore be easily accessible in order to transport the electricity (Yoo et al., 2017). The generation, transmission, distribution and management of electricity are traditionally focused around existing power grids (Colak et al., 2016). In sophisticated power networks, interconnected systems that are complex and geographically spread out must be managed; maintaining secure and stable supply that can be accurately monitored is the daily operational imperative (Palukuru et al., 2014; Mohanty et al., 2016). Ensuring system stability and security is therefore a prime focus. To make an optimal use of present day power systems, boosting capacity by introducing flexible/AC transmission systems (FACTS) controllers is essential (Bathina and Gundavarapu, 2014). Basically, this means using different components to better control the flow of electricity within power systems (Ali and Abd-Elazim, 2012).

FACTS devices can be divided into three groups. All of them incorporate various components (Jordehi, 2015; Pahlavani and Mohammadpour, 2011). Currently, static synchronous compensators (STATCOMs) are widely used (Xu and Li, 2014; Ganguly, 2014). Since then, unified power flow controllers (UPFCs) can control the voltage, impedance and phase angle in transmission lines have been added to these devices (Khodabakhshian et al., 2016). UPFCs have proven to be surprisingly effective for upgrading power system damping, particularly for between territory motions by utilising a balancing out signal in the control system (Pradhan et al., 2016). It is well known that the hereditary algorithm (HA) (Hassan et al., 2013), fuzzy logic (FL) (Mok et al., 2005), particle swarm optimisation (PSO) (Shayeghi et al., 2010) and differential evolutionary (DE) (Sahu et al., 2015) are all connected for dealing with instability issues that relate to soft-computing techniques. Traditional optimisation, heuristic and artificial intelligence techniques for various systems can all be used to reconfigure networks (Vijay Kumar and Srikanth, 2015a). Nonetheless, deriving hybrid calculations from fundamental issues, then applying them to specific power systems has been shown to be remarkably effective (Chitra and Devarajan, 2014).

To improve the dynamic constancy of power systems, various researchers have proposed using the cuckoo search (CS) and firefly algorithm (FA) under UPFCs placement and capacity (Vijay Kumar and Srikanth, 2017). To dispose the impact of UPFCs, Mehrjerdi and Ghorbani (2017) discussed a strategy and flaw obstruction at the separation 
hand-off as they relate to synchronised phases. Packiasudha et al. (2017) pointed out that the dynamic and detached mass communications consider the various researchers presented the cumulative gravitational search algorithm (CGSA) with the goal of effectively reviewing the resultant power acquired between the majorities.

Motiebirjandi and Fateh (2017) have proposed combining multiple UPFCs, and utilising basic modes of the system and build-up factor to expand electromechanical motions damping within the electric power systems. Kavitha and Neela (2017) discuss a primary capacity comprising cost, loadings of line, and deviations in the load voltage planned to gain more advantages out of their establishment; and the loads designated to them that decide their relative significance. Abd-Elazim and Ali (2016a) have presented imperialist competitive algorithm (ICA), a new optimisation system, for STATCOM in a multimachine network. Pressure volume (PV) curves were represented to find the STATCOM best area. Abd-Elazim and Ali (2016b) presented a new optimisation calculation in single and multi-machine control framework, specifically gravitational search algorithm (GSA) for outlining static synchronous series compensator (SSSC). For measuring and perfect allotment of distributed generation (DG) in the source of distribution networks, the antlion optimisation algorithm (ALOA) was presented (Ali et al., 2016). In this paper, a more efficient calculation is recommended to examine the load flow problem and resolve the problems with UPFCs. In Section 2, a more detailed explanation of the recommended technique is given. In Section 3, the results are displayed. The report is concluded in Section 4.

\section{Modelling UPFC devices}

\subsection{A UPFC device model}

Figure 1 depicts the layout of the transmission line with the UPFCs connected to $i$ th and $j$ th buses. It is essential that Converter 2 is getting a genuine power request at a basic direct current (DC) interface terminal from an alternating current (AC) of control framework from Converter 1. Likewise, Converter 1 can create or consume receptive power at its terminal of $\mathrm{AC}$, which is independent of exchange of dynamic capacity to the DC terminal. Thus, indirect voltage control is to be implemented at the input terminal of the UPFCs because of the capacity of an autonomous advanced static var compensator (SVC) giving reactive power pay to the transmission line (Reddy et al., 2017). At the fundamental recurrence, Converter 2 is used to produce voltage. The inverter output voltage infused in series with line can be used as direct voltage control, arrangement remuneration, stage shifter and their blends. At its DC terminal by the special types of controls connected and exchanges active power, this voltage within can produce or retain all the required reactive power (Ali et al., 2017).

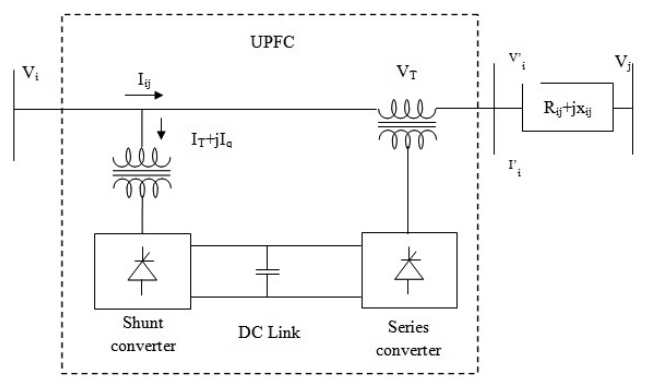

Figure 1. Basic schematic diagram of UPFCs.

Magnitude of embedded voltage $\left(V_{T}\right)$, angle of inserted voltage $\left(d_{T}\right)$ and magnitude of the current $\left(I_{q}\right)$ are the UPFC's controllable parameters. The equation for the power flow is written as follows:

$$
\begin{aligned}
& S_{i j}^{u}=P_{i j}^{u}+Q_{i j}^{u}=V_{i} I_{i j}^{*}=V_{i}\left[I_{\text {shunt }}+I_{i}^{\prime \prime}+\left(I_{r}+I_{q}\right)\right]^{*}, \\
& S_{i j}^{u}=P_{i j}^{u}+Q_{i j}^{u}=V_{j}\left(I_{\text {shunt }}-I_{i}^{\prime \prime}\right)^{*} .
\end{aligned}
$$

UPFC with the active and reactive power flow in lines can be expressed as:

$P_{i j}^{u}=\left(V_{i}^{2}+V_{i}^{2}\right) G_{i j}+2 V_{i} V_{T} G_{i j} \cos \left(\delta_{T}-\delta_{i}\right)-V_{j} V_{T}\left[G_{i j} \cos \left(\delta_{T}-\delta_{j}\right)+B_{i j} \sin \left(\delta_{T}-\delta_{j}\right)\right]$

$-V_{i} V_{j}\left[G_{i j} \cos \delta_{i j}+B_{i j} \sin \delta_{i j}\right]$

$Q_{i j}^{u}=-V_{i} I_{q}-V_{i}^{2}\left(B_{i j}+B / 2\right)-V_{i} V_{T}\left[G_{i j} \sin \left(\delta_{r}-\delta_{i}\right)+B_{i j} \cos \left(\delta_{r}-\delta_{i}\right)\right]$

$-V_{i} V_{j}\left[G_{i j} \sin \delta_{i j}-B_{i j} \cos \delta_{i j}\right]$

$P_{j i}^{u}=V_{i}^{2} G_{i j}-V_{j} V_{i}\left[G_{i j} \cos \delta_{i j}-B_{i j} \sin \delta_{i j}\right]-V_{j} V_{T}\left[G_{i j} \cos \left(\delta_{T}-\delta_{j}\right)-B_{i j} \sin \left(\delta_{T}-\delta_{i}\right)\right]$,

$Q_{j i}^{u}=-V_{j}^{2}\left(B_{i j}+B / 2\right)+V_{i} V_{j}\left[G_{i j} \sin \left(\delta_{i j}+B_{i j} \cos \delta_{i j}\right]-V_{j} V_{T}\left[G_{i j} \sin \left(\delta_{T}-\delta_{j}\right)+B_{i j} \cos \left(\delta_{T}-\delta_{j}\right)\right]\right.$

Figure 5 provides a basic circuit theory for the equivalent circuit. $i$ and $j$ are the active power at bus $\left(P_{i u}\right.$ and $\left.P_{j u}\right)$; and reactive powers $\left(Q_{i u}\right.$ and $\left.Q_{j u}\right)$ of a line are:

$$
\begin{aligned}
& P_{i u}=-V_{T}^{2} G_{i j}-2 V_{i} V_{T} G_{i j} \cos \left(\delta_{T}-\delta_{j}\right)+V_{j} V_{T}\left[G_{i j} \cos \left(\delta_{T}-\delta_{j}\right)+B_{i j} \sin \left(\delta_{T}-\delta_{j}\right)\right], \\
& P_{j u}=V_{j} V_{T}\left[G_{i j} \cos \left(\delta_{T}-\delta_{j}\right)-B_{i j} \sin \left(\delta_{T}-\delta_{j}\right)\right], \\
& Q_{i u}=V_{i} I_{q}+V_{i} V_{T}\left[G_{i j} \sin \left(\delta_{T}-\delta_{j}\right)+B_{i j} \cos \left(\delta_{T}-\delta_{j}\right)\right] \\
& Q_{i u}=-V_{j} V_{T}\left[G_{i j} \sin \left(\delta_{T}-\delta_{j}\right)+B_{i j} \cos \left(\delta_{T}-\delta_{j}\right)\right] .
\end{aligned}
$$

To evaluate the optimal size of FACTS devices, their cost functions are evaluated with mathematical formulae expressed in the following equations. The cost of installing a UPFC $\left(U_{C}\right)$ can be derived from the following: 


$$
\begin{aligned}
& U_{C}=0.0003 S^{2}-0.2691 S+188.22, \\
& S=\left|Q_{2}\right|-\left|Q_{1}\right| .
\end{aligned}
$$

Where $Q_{2}$ is the flow of responsive power in the line subsequent to introducing FACTS gadget in mega volt ampere reactive (MVAR) and $Q_{1}$ is the progression of responsive power in the line after introducing a FACTS gadget in MVAR. In this paper, UPFCs are used to analyse the system voltage stability, while the UPFCs vector in the optimisation process can be described as follows.

$$
\mathrm{Y}_{i}=\left(y_{1}, y_{2}, y_{3}, \ldots . y_{n}\right)
$$

Where $n$ represents the $i$ th FACTS device location. Installing more than one FACTS device in any one branch or bus is not allowed (Deepa and Rizwana, 2015).

\subsection{Objective functions}

Identifying the UPFC device optimal location and sizing is planned as a multi-target optimisation issue utilising Equation (13):

$$
\begin{aligned}
& O B_{f}=\operatorname{Min}(\zeta), \\
& \text { where } \zeta=\zeta^{\prime}, \\
& \zeta^{\prime}=\Phi_{1} \zeta_{1}\left(V_{d}\right)+\Phi_{2} \zeta_{2}\left(O_{l}\right)+\Phi_{3} \zeta_{3}\left(P_{l}\right)+\zeta_{4}\left(U_{c}\right) .
\end{aligned}
$$

In Equation (14), $V_{d}, O_{l}, P_{l}$ and $U_{c}$ denote the voltage deviation, overloads of transmission line, power loss and cost of the UPFC device, respectively. In transmission lines to minimise overloads, using the equations, its corresponding metric is computed,

$$
\zeta_{2}\left(O_{l}\right)=\sqrt{\sum_{i=1}^{i=N_{l}}\left(P_{i}-P_{\max }\right)^{2}} .
$$

Where $P_{i}$ and $P_{\max }$ represent the power flow and limit of $i$ th transmission line, respectively.

Voltage deviation is evaluated based on the same conditions. It is described as follows:

$$
\zeta_{1}\left(V_{d}^{i}\right)= \begin{cases}\left(1-V_{i}\right)^{2} & \text { if } 1.05 \leq V_{i} \leq 1.1 \\ \left(5-V_{i}\right)^{2} & \text { if } V_{i}>1.1 \\ 0 & \text { others }\end{cases}
$$

Where $V_{i}$ represents the $i$ th bus of power system voltage magnitude. After that, the system power loss is evaluated from the following equation:

$$
\zeta_{3}\left(P_{l}\right)=\sum_{j=1}^{N}\left|V_{i}\right|\left|V_{j}\right|\left|Y_{i j}\right| \cos \left(\theta_{i j}-\delta_{i}+\delta_{j}\right) .
$$

The third goal is to limit losses within a power system. The capacity loss is computed simply for each branch. The above-mentioned objectives are all denoted by $\zeta 1, \zeta 2$ and そ3 (Shrawane et al., 2015).

\subsection{Optimal location and capacity selection based on ALOA and invasive weed optimisation (IWO) algorithms}

The UPFCs device's optimal location and sizing are resolved in respect of the bus system's dynamic stability. In view of the dynamic security investigation, the optimal location and capacity have been recognised. For the dynamic assessment, the proposed algorithm is connected to the framework. In this paper, the ALOA and IWO calculation are combined to evaluate the UPFCs' location. In the underlying procedure, the position of a UPFC device can be resolved using the ALOA; the infused capacity is assessed by the IWO algorithm. Due to the respect of the wellness work, the infused capacity is resolved. In the wellness work, the voltage deviation, overload transmission line and power loss are indicated. In light of the Newton Raphson (N-R) approach, the typical power loss and voltage values are resolved. From that point onward, in other words, during the load variety period, the maximum power loss bus is distinguished for settling the UPFCs utilising ALOA. After the situation of UPFCs, the target functions are assessed accordingly and the infusion capacity is resolved by IWO algorithm. IWO algorithm is used to upgrade the dynamic stability and recoup the normal operating condition. The general working procedure of the proposed strategy in the related section is to be explained.

\subsubsection{ALOA for optimal placement}

In this paper, the ALOA is used to decide the arrangement of a UPFC. The transport information, real and responsive power, power loss and voltage are the algorithm of input. The bus number, which is randomly created, assesses power losses within the system that can be addressed by various possible arrangements. The objective function of the calculation is determined as the maximum power loss bus for settling the UPFCs. The detailed antlion optimiser (ALO) calculation process is shown in the accompanying area (Reddy et al., 2017).The progression method of the proposed algorithm can be simply expressed as:

Creating irregular walks of ants: Irregular strolls are founded on the following equation:

$X(t)=\left\lfloor 0, \operatorname{cumsum}\left(2 r\left(t_{1},-1\right), \operatorname{cumsum}\left(2 r\left(t_{2},\right)-1\right), \ldots \operatorname{cumsum}\left(2 r\left(t_{n},-1\right)\right\rfloor\right.\right.$. 
Where cumsum computes the cumulative sum, $n$ is the extreme number of cycles, $t$ denotes the propagation of irregular walk and $r(t)$ is a stochastic function considered as follows:

$$
r(t)=\left\{\begin{array}{l}
1 \text { if rand }>0.5 \\
0 \text { if rand } \leq 0.5
\end{array}\right.
$$

\section{1) Trapping with antlion pits}

The antlion cages are influenced by the irregular strolls of ants. The accompanying conditions are proposed to numerically model this supposition:

$$
\begin{aligned}
& \gamma_{i}^{t}=\operatorname{Antlion}_{j}^{t}+\gamma^{t}, \\
& \lambda_{i}^{t}=\operatorname{Antlion}_{j}^{t}+\lambda^{t} .
\end{aligned}
$$

Where $\gamma^{t}$ and $\lambda^{t}$ are the base and limit of all variables.

\section{2) Building traps}

To show the chasing capacity of antlions, the roulette wheel was utilised. During optimisation, according to their fitness to pick antlions, the ALOA needs a roulette wheel administrator. The technique gives more accurate fitter antlions probabilities of catching ants.

\section{3) Making ants slide towards the antlion}

With the proposed method, ants are needed to move randomly and in respect to their wellness. Antlions are able to create traps.

\section{4) Getting prey and re-assembling the pit}

The last stage of hunting occurs when an ant comes to the very base of the pit and is trapped in the antlions jaw. The equation is given as follows:

$$
\left(A L_{j 1}, A L_{j 2}, \ldots . . A L_{j d}\right)=\left(A_{i 1}, A_{i 2}, \ldots A_{i d}\right) \text { if } f\left(\text { Ant }_{i}^{t}\right)>f\left(\text { Antlion }_{j}^{t}\right) .
$$

Where $t$ shows the current iteration, Antlion $_{j}^{t}$ shows the position of the selected $j$ th antlion at the $t$ th iteration and Ant ${ }_{i}^{t}$ indicates the position of the $i$ th ant at the $t$ th iteration.

\section{5) Fitness evaluation}

The equation for the objective function can be formulated by Equation (23).

$$
F_{i}^{j}=\min \left(\zeta_{2}\left(P_{L}\right)\right)
$$

\section{6) Elitism}

To preserve the obtained best solution, the situation of the best (fittest) antlion is spared as being the first class at each stage. The equation is derived as follows:

$$
A n t_{i}^{t}=R M_{\text {antlion }}^{t}+R_{\text {Elite }}^{t} / 2
$$

Where $R_{\text {Elite }}^{t}$ is the irregular stroll of world class at $t$ th iteration, and $R M_{\text {antlion }}^{t}$ is the arbitrary stroll around the antlion chosen at the $t$ th iteration (Ali et al., 2017). Based on the target work, the UPFCs are located optimally and receive the optimal outputs and corresponding transport framework. The process is terminated until the greatest emphasis is achieved and the procedure above is continued. IWO algorithm is performed for the capacity evaluation process. The detailed process of the IWO algorithm is shown below.

\subsubsection{IWO algorithm for optimal capacity selection}

Predicting the optimal capacity of a UPFC device is considered. How to achieve the optimal capacity for FACTS devices is to be discussed in the accompanying diagram. The numerical stochastic and subsidiary free optimiser are both IWO calculation (Nagib et al., 2017). Propagation, spatial dispersal and competitive prohibition are the procedures derived from the colonising behaviour (Figure 2) (Yahyatabar and Najafi, 2017). The sketch technique of the essential IWO can be summarised as follows (Velmurugan et al., 2016):

\section{Step 1: Initialisation}

In the first step, the voltage and power values are initiated and population of initial weeds, $X=\left\{x_{1}, x_{2}, \cdots, x_{P S_{0}}\right\}$. The size of an initial population is $P S_{0} ; X=\left\{x_{i 1}, x_{i 2}, \cdots, x_{i n}\right\}$; is an n-dimensional vector real valued. Each dimension $x_{i k}$ of $x_{i}$ can be generated as follows:

$$
x_{i k}=l b_{k}+r .\left(u p_{k}-l b_{k}\right), i=1,2, \ldots . P S_{0}, k=1,2, \ldots . n .
$$

Bounds are problem dependent, where $r$ is a uniform irregular number $[0,1]$ and $k$ denotes the lower and upper limits measurement $l b_{k}$ and $u p_{k}$.

\section{Step 2: Wellness evaluation}

The wellness process is assessed and computed using the following equation: 


$$
F_{i}=\min (\zeta)
$$

For evaluating $\zeta$, the objective function is determined.

\section{Step 3: Reproduction}

The weeds produce seeds during reproduction and more seeds are produced by the fitter weed. The quantity of seeds produced by weed $x_{i}$ is $s_{i}$ as follows:

$$
s_{i}=\text { floor. }\left(s_{\min }+\frac{s_{\max }-s_{\min }}{f_{\max }-f_{\min }} \cdot\left(f\left(x_{i}\right)-f_{\min }\right)\right) \text {. }
$$

Where $S_{\min }$ and $S_{\max }$ are the worst and best weeds respectively in the population. $f\left(x_{i}\right)$ is the wellness of $x_{i} . f_{\min }=\min _{x_{i} \in X} f\left(x_{i}\right)$. floor () is the closest whole numbers towards the less interminability.

The weed seeds $x_{i}$ are closely spread around it. According to the normal distribution for $x_{i}$, the IWO algorithm generates a seed. Denote $X_{i}^{\prime}=\left\{x_{i 1}^{\prime}, x_{i 2}^{\prime}, \ldots \ldots . x_{i n}^{\prime}\right\}$ a seed produced by $x_{i}$. We have:

$$
X_{i k}^{\prime}=x_{i k}+N\left(0, \sigma^{2}\right), k=1,2, \ldots, n
$$

The distributed random number is $N\left(0, \sigma^{2}\right), \sigma$ is the standard deviation.

\section{Step 4: Spatial dispersal}

Seeds are scattered near their parent weeds with a normal distribution. From a specified initial value $\sigma_{o}$ to a final value $\sigma_{f}$, the standard deviation $\sigma$ of the normal distribution is reduced flexibly as follows:

$$
\sigma_{\text {iter }}=\frac{\left(\text { iter }_{\max }-i t e r\right)^{\alpha}}{\left(\text { iter }_{\max }\right)^{\alpha}} \cdot\left(\sigma_{o}-\sigma_{f}\right)+\sigma_{f} .
$$

Where $\sigma_{\text {iter }}$ is the standard deviation at the present cycle, $\alpha$ is a nonlinear regulation file and iter $_{\max }$ is the greatest number of cycles. Normally, $\alpha$ is set to 3 .

\section{Step 5: Focused exclusion}

For the next generation, all plants and their seeds are combined to frame a populace. Less fit weeds are eliminated if the population size is higher than a given esteem $P S_{\max }$.

\section{Step 6: Termination condition}

Until a given termination term, repeat Steps 2 through 5. From IWO algorithm output, the optimal results are calculated and optimal objective function is evaluated. A detailed description of the performance analysis with diagrams is presented in the following section.

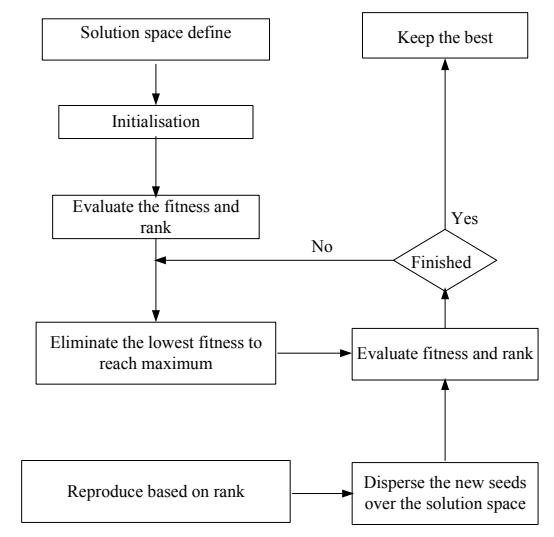

Figure 2. Proposed diagram of IWO calculation.

\section{Results and discussion}

In this paper, a more efficient method is proposed to improve the dynamic stability of transmission systems when using UPFCs devices. ALO and IWO are utilised to ascertain the UPFCs devices' optimal locations and capacities. The matrix laboratory (MATLAB)/Simulink is achieved in the proposed method.

\section{(i) Test system 1: Institute of Electrical and Electronics Engineers (IEEE) 30 transport framework}

To analyse the efficacy of the proposed strategy, compared with existing methods, it was utilised that: the IEEE 30 transport framework, comprising six generator transports, 21 burden transports and 42 transmission lines (Bhattacharya and Chattopadhyay, 2010). The dynamic steadiness of the IEEE 30 bus system was evaluated by using the proposed method. Initially, the framework load flow was examined using the standard N-R strategy. The execution of IEEE 30 transport system of voltage, with real and receptive power, was dissected by applying the N-R approach. From here onwards, the over-burdening was connected to the particular bus, and later the comparative voltages and power loss were resolved. In the N-R approach, the real and reactive power, and voltages values were organised as shown in Table 1.

The particular bus and lines are affected during the over-burdening period; therefore, the voltage deviation and power loss of the relating buses need to be assessed. During the over-burdening condition, the maximum power loss transport is distinguished which is considered as the weak buses for settling the FACTS gadgets. UPFC devices are viewed as the optimal location of UPFC devices are distinguished as the maximum power loss bus. In the investigation, FACTS devices optimal locations are allotted according to their needs in view of their maximum losses. 
In view of the investigation, the location, sizing and number of UPFCs devices are resolved. PSO is used to assess the greatest power misfortune transport. The PSO is used to determine the greatest power; misfortune transport is relegated for settling the FACTS devices. The quantity of devices and optimal locations are chosen and controlled by using the PSO calculation. The capacity and cost of UPFC devices are then evaluated using the ALO. To demonstrate the proposed strategy's effectiveness, four arrangements of examination were conducted: overburdening the buses 4 and 12 individually. Implementing the proposed technique is then compared with other methods such as PSO and ALO techniques.

Table 1. Optimal locations and per values of UPFCs.

\begin{tabular}{|c|c|c|c|c|c|c|c|c|}
\hline \multirow{3}{*}{ UPFC } & \multirow{3}{*}{$\begin{array}{l}\text { Optimal } \\
\text { Locations }\end{array}$} & \multirow{3}{*}{$\begin{array}{c}\text { From } \\
\text { bus }\end{array}$} & \multirow{3}{*}{$\begin{array}{l}\text { To } \\
\text { bus }\end{array}$} & \multirow{3}{*}{$\begin{array}{r}\text { Injected } \\
\text { power }\end{array}$} & \multicolumn{2}{|c|}{ From bus } & \multicolumn{2}{|c|}{ To bus } \\
\hline & & & & & $\begin{array}{l}\text { Shunt } \\
\text { vSC }\end{array}$ & Series/VSC & $\begin{array}{l}\text { Shunt } \\
\text { vSC }\end{array}$ & $\begin{array}{l}\text { Series } \\
\text { vSC }\end{array}$ \\
\hline & & & & & $\mathbf{P}$ & $\mathbf{Q}$ & $\mathbf{P}$ & $\mathbf{Q}$ \\
\hline 1 & 4 & 3 & 4 & 12.2561 & 6.2258 & -20.143 & 63.8320 & -182.0245 \\
\hline 2 & 8 & 5 & 7 & 3.8112 & 0.0276 & -7.2546 & 40.1619 & 3.9245 \\
\hline 3 & 23 & 18 & 19 & 18.4536 & -24.7845 & -6.0258 & 9.6902 & 7.5365 \\
\hline 4 & 15 & 4 & 12 & 10.4258 & -80.6126 & -105.2541 & 91.224 & 1.8268 \\
\hline 5 & 20 & 14 & 15 & 3.1247 & 44.2561 & -20.1225 & -12.9514 & -2.2235 \\
\hline
\end{tabular}

Table 2. Analysis of deviation, cost and overloading after connecting UPFCs.

\begin{tabular}{ccccccc}
\hline UPFC & $\begin{array}{c}\text { Optimal } \\
\text { locations }\end{array}$ & $\begin{array}{c}\text { From } \\
\text { bus }\end{array}$ & $\begin{array}{c}\text { To } \\
\text { bus }\end{array}$ & $\begin{array}{c}\text { Voltage } \\
\text { deviation } \\
\text { (p.u) }\end{array}$ & Overloading & Cost (\$/KVAR) \\
\hline 1 & 4 & 3 & 4 & 1.0184 & 0 & 186.3245 \\
2 & 8 & 5 & 7 & 1.1369 & 0 & 187.2541 \\
3 & 23 & 18 & 19 & 1.015 & 0.254 & 184.3562 \\
4 & 15 & 4 & 12 & 0.4235 & 1.5628 & 178.3654 \\
5 & 20 & 14 & 15 & 0.9936 & 0 & 186.2548 \\
6 & 17 & 12 & 14 & 0.2436 & 0.1751 & 179.2134 \\
\hline
\end{tabular}

During over-burdening of Bus 4, the maximum power loss bus must be decided. As indicated by their need, the maximum power loss buses are identified, which are then allocated as the optimal locations for fixing the UPFCs devices. Here, five optimal locations are identified for settling the UPFC devices. Also, 12 UPFC devices are incorporated into the bus system. As per Table 3, the UPFC is analysed and the corresponding results are assessed. With UPFCs devices, the $P$ and $Q$ estimations of shunt and series vehicle stability control (VSC) are resolved. As a result of associating UPFCs, the voltage deviation, over-burdening and cost are investigated and organised (shown in Table 2). The line flow limit applies to confirm the infringement of line limits as a result of settling the issue which displays the security limits. Furthermore, power loss within the system is assessed. The system's normal loss is $10.8095 \mathrm{MW}$. In an over-burdening condition, the loss increases to 12.2565 MW. The UPFCs device optimal location is settled in the eighth bus. From here onwards, the loss is reduced to 8.8691 MW.

Figure 3 shows the IEEE 30 transport framework's normal transport voltage profile. In this section, the power flow initiated by the proposed method after the single generator problem of IEEE 30 transport framework is summarised. Figure 4(a) demonstrates the second bus generator fault voltage profile. The N-R can keep the bus voltage at a stable margin when the power stream is ordinary. When there is an issue in a generator, the bus voltage faces instability. To limit voltage instability, the strategy for a proposed technique is utilised to decide the optimal location and capacity for UPFCs. Figure 4(b) demonstrates the voltage profile under generator fault in the sixth bus. Proposed technique effectively endeavours to keep up the voltage profile and stability. In addition, faults presented in other generator buses 13, 22, 27 and comparing yields are portrayed in Figures 4(c), 4(d) and 4(e). Figure 5 demonstrates the voltage examination at a single generator problem of IEEE 30 bus system with various techniques like GSA-Bat algorithm, FA-CS, and ALO-invasive weed optimisation algorithm (IWOA).

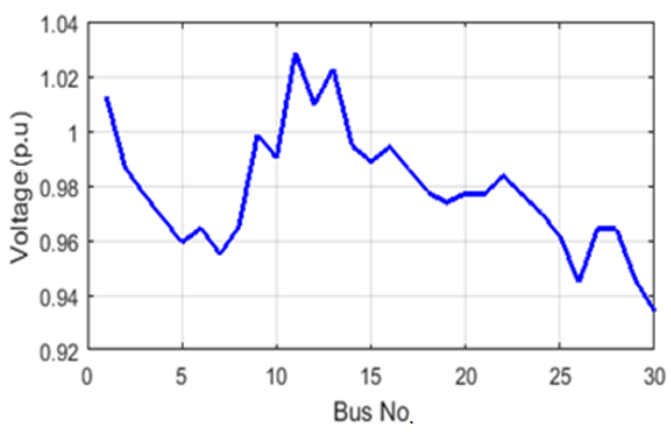

Figure 3. Normal bus voltage profile. 

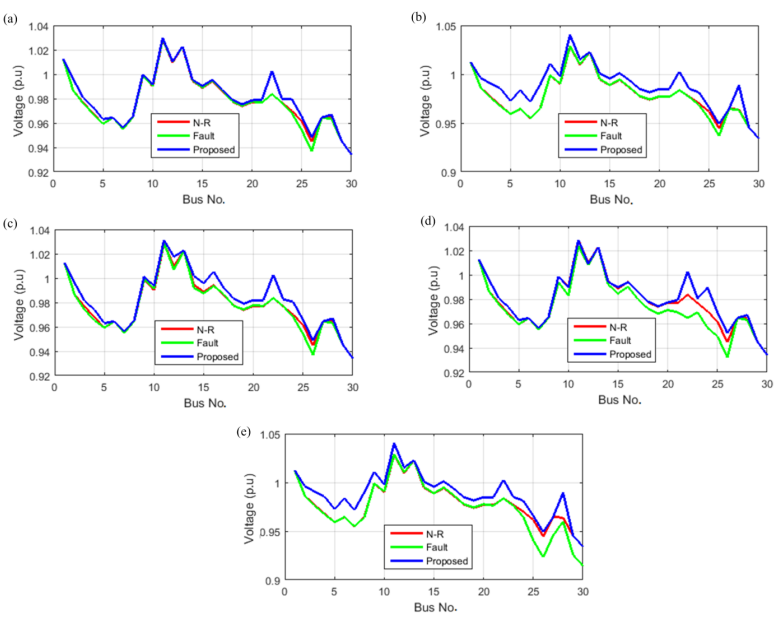

Figure 4. Power profile under (a) 2nd bus generator fault; (b) 6 th bus generator fault; (c) 13th bus generator fault; (d) 22nd bus generator fault; and (e) 27 th bus generator.

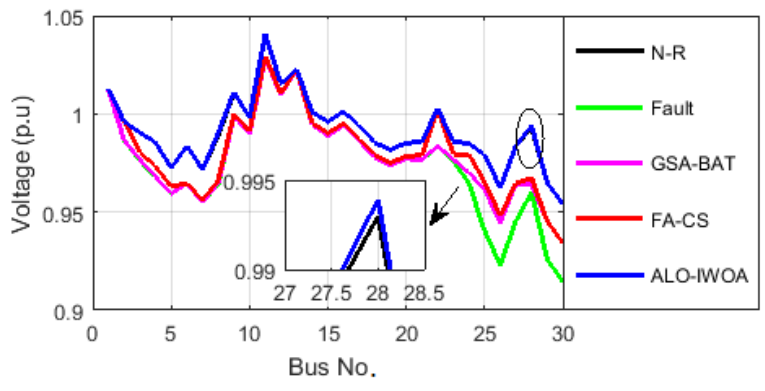

Figure 5. Voltage profile comparison with single generator issue.

Different states of the double generator fault, and various voltage profiles in the bus system when using the proposed techniques are resolved and plotted in Figures 6(a) - 6(e). Correlations are shown in a fault condition when using the proposed strategy. In the bus system that enlarges the stability margin, the double generator defect drives the ordinary voltage level. As suggested by the range of defects, the proposed method found the UPFCs position and size to reduce costs. This approach is used to determine the voltage instability issue. The IEEE 30 bus system in the double generator is compared and in fault condition; the proposed method offers a better yield. Figure 7 demonstrates the voltage profile examination at 6 and 13 bus generators of IEEE 30 bus system with various techniques like GSA-Bat algorithm, FA-CS, and ALO-IWOA. Compared with existing procedures, the proposed technique yields better results.
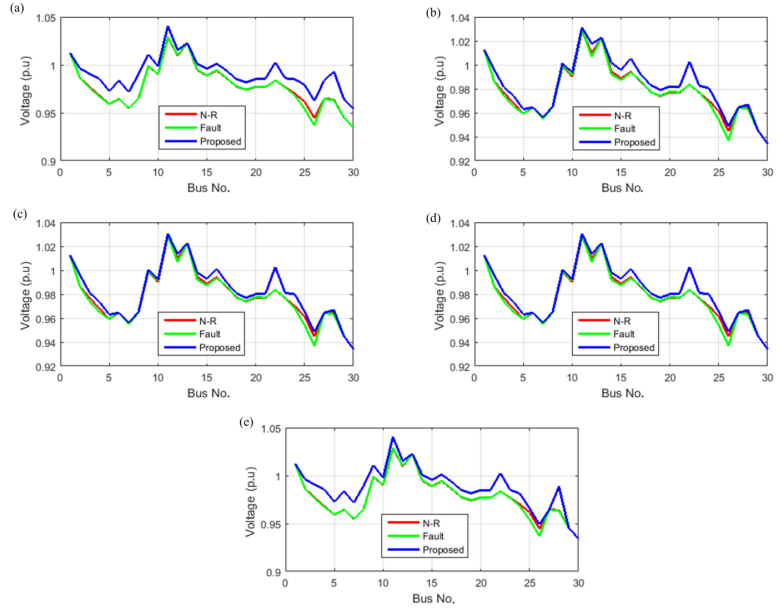

Figure 6. Generator defect cause by voltage profile at: (a) buses 2 and 6; (b) buses 2 and 13; (c) buses 6 and 13; (d) buses 13 and 27; and (e) buses 22 and 27.

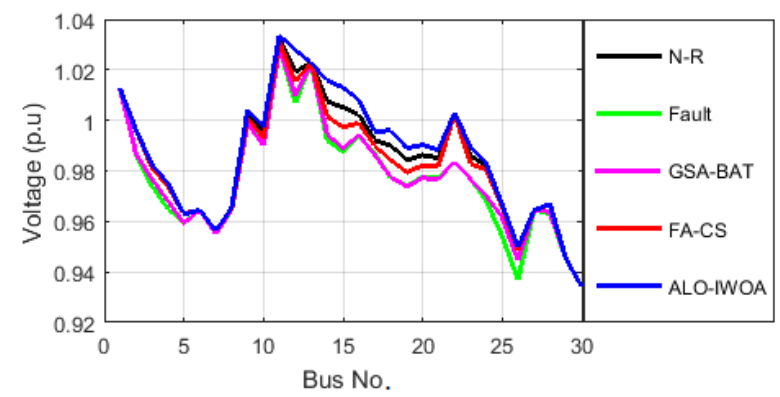

Figure 7. Comparison of voltage profile at double generator issue.

Table 3. Comparison analysis of power loss and cost with various methods.

\begin{tabular}{|c|c|c|c|}
\hline Methods & $\begin{array}{l}\text { Power loss in } \\
\text { (MW) }\end{array}$ & Methods & $\begin{array}{c}\text { Costs } \\
(\$ / \text { KVAR })\end{array}$ \\
\hline Proposed (ALO-IWO) method & 8.8691 & & \\
\hline PSO & 10.0214 & Proposed & \\
\hline ALO & 9.2354 & (ALO-IWO) & 174.2581 \\
\hline $\begin{array}{c}\text { Genetic algorithm (GA) (Subramaniam } \\
\text { and John Basha, 2015) }\end{array}$ & 18.30 & method & \\
\hline $\begin{array}{c}\text { Ant colony optimisation (ACO) } \\
\text { (Subramaniam and John Basha, 2015) } \\
\text { Gravitational search algorithm (GSA) } \\
\text { (Subramaniam and John Basha, 2015) }\end{array}$ & 17.7451 & PSO & 180.2156 \\
\hline $\begin{array}{l}\text { Imperialist competitive algorithm (ICA) } \\
\text { (Subramaniam and John Basha, 2015) }\end{array}$ & 16.48 & & \\
\hline $\begin{array}{l}\text { Hybridgenetic Algorithm -particle swarm } \\
\text { optimisation (GAPSO) }\end{array}$ & 9.4652 & ALO & 178.2658 \\
\hline approach(Shrawane et al., 2015) & & & \\
\hline $\begin{array}{l}\text { With UPFC voltage injection model } \\
\text { (Emily and Shunmugalatha, 2015) }\end{array}$ & 15.598 & $\begin{array}{c}\text { Bat and firefly } \\
\text { algorithm }\end{array}$ & \\
\hline $\begin{array}{l}\text { With UPFC negative impedance model } \\
\text { (Ali et al., 2017) }\end{array}$ & 15.88 & $\begin{array}{l}\text { (Kumar and } \\
\text { Srikanth, 2016) }\end{array}$ & 176.8095 \\
\hline
\end{tabular}


Moreover, the costs, voltage deviations and losses are investigated (shown in Table 3 ). The investigation above reveals that, compared with other techniques, the proposed strategy is exceptionally effective at reducing deviation, power losses and costs. In Tables 1, 2 and 3, the proposed method is tried with the arranged IEEE 30 transport framework.

Table 3 shows the given means of general targets, the proposed method achieves overall reduction objectives, and surpassing existing strategies. The table also demonstrates that the proposed method is superior to other algorithm by minimising power loss and reducing costs. The proposed method achieves low estimations of energy problems in transport. The proposed method prompts the greatest reductions and estimation of energy problems among all optimisation algorithms. For example, the loss achieved by the proposed method is $8.8691 \mathrm{MW}$, lower than the one from the ALO and PSO techniques. Additionally, the cost of the UPFC devices is favourable compared with existing techniques. The cost of the UPFCs with the proposed method is 174.2581 \$/KVAR as compared with those of the FA-Bat algorithm, PSO and ALO techniques which are 176.8095 \$/KVAR, 180.2156 \$/KVAR and 178.2658 $\$ /$ KVAR respectively. The suggested validation for UPFC units can be found in Tables 1- 3. In general, the use of UPFCs affirms that the proposed strategy is a reliable optimisation paradigm, and it provides additional proof for effectiveness by improving the over-burdening outcomes that occur to power systems and the results accomplished by assigning a UPFC.

Table 4. Power departure at single generator problem.

\begin{tabular}{cccccccc}
\hline \multirow{2}{*}{$\begin{array}{c}\text { Fault } \\
\text { generator }\end{array}$} & \multicolumn{2}{c}{ Best location } & \multicolumn{5}{c}{ Power loss at single generator MV } \\
\cline { 2 - 7 } & From & To bus & Normal & Fault & GSA-BAT & FA-CS & Proposed \\
& bus & & & & & & \\
\hline 2 & 3 & 5 & 13.36 & 15.42 & 12.22 & 11.11 & 9.12 \\
\hline
\end{tabular}

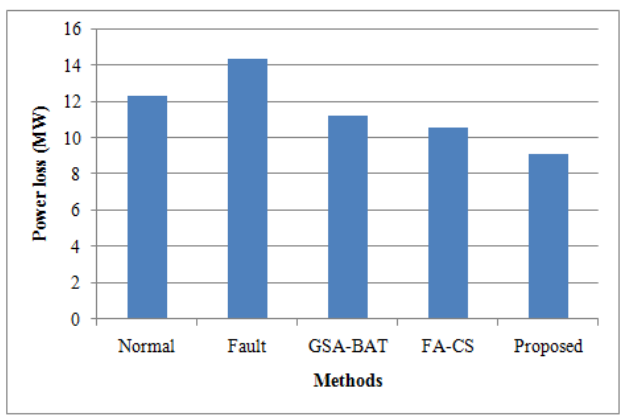

Figure 8. Comparison of power loss at single generator defect.

Table 4 shows the power loss correlation using different techniques of IEEE 30 transport system. When the faults are connected in the 27 th bus diverse systems such as
GSA-Bat algorithm, FA-CS and ALO-IWOA are analysed. Figure 8 demonstrates various other techniques and the proposed technique for power loss in a single generator. The single generator control loss of IFEE 30 transport structure is easily reduced to $9.12 \mathrm{MW}$ by utilising a proposed strategy which gives a better yield. In Table 5, a power loss comparison in IEEE 30 bus systems using various methods is shown. Diverse strategies include GSA-Bat algorithm, FA-CS, ALO-IWOA, when fault is connected in the 6th and 13th buses. Figure 9 demonstrates the variation between different techniques and a proposed strategy for power loss in a double generator. Power loss with IEEE 30 transport framework in a double generator is effectively reduced to 9.67 MW using the proposed strategy which clearly gives a better yield.

Table 5. Power departure at the double generator problem.

\begin{tabular}{cccccccc}
\hline \multirow{2}{*}{$\begin{array}{c}\text { Fault } \\
\text { generator }\end{array}$} & \multicolumn{2}{c}{ Best location } & \multicolumn{5}{c}{ Power loss at double generator (MV) } \\
\cline { 2 - 7 } & From & To bus & Normal & Fault & GSA-BAT & FA-CS & Proposed \\
& bus & & & & & & \\
\hline 6 and 13 & 10 & 23 & 14.36 & 17.42 & 13.22 & 11.56 & 9.67 \\
\hline
\end{tabular}

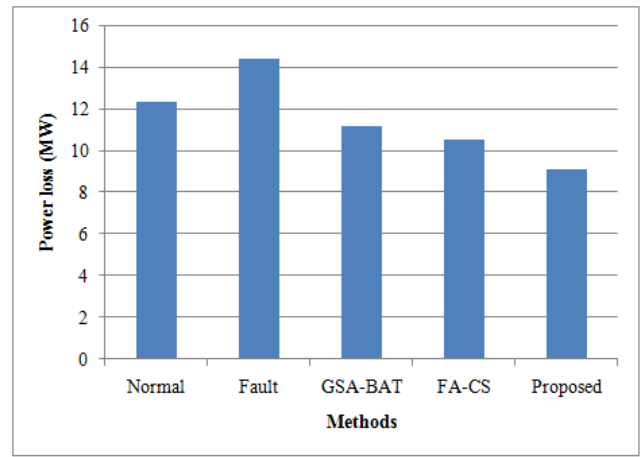

Figure 9. Power loss comparison with double generator fault.

\section{(ii) Test system 2: IEEE 14 transport structure}

In this section, the performance of the proposed method is discussed and verified through the IEEE 14 transport framework. The two sources of IEEE 14 transport framework are a slack bus and a second bus. Using N-R burden stream investigation, it is predicted under normal terms and the entire system of load flow parameters is bus voltage and power loss. At the second transport, the single generator issue is received. The power flow difficulties are maximum power misfortune and voltage stability. These challenges can be overcome by finding the position of the defect and locating UPFCs with proper capacities. 


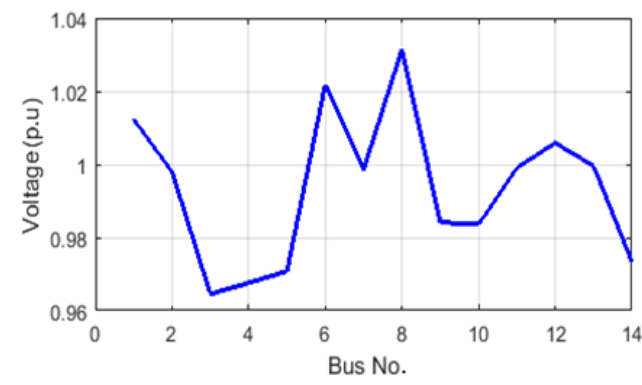

Figure 10. Normal bus voltage.

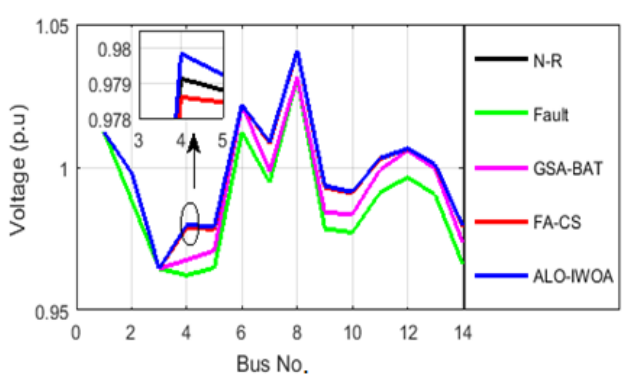

Figure 11. Voltage profile comparison at single generator problem.

In Figure 10, the normal bus voltage profile of IEEE 14 transport framework during N-R burden stream investigation is observed. Under various topologies, the voltage profile examination at single generator issue of IEEE 14 transport framework is observed in Figure 11. GSA-Bat algorithm, FA-CS and ALO-IWOA strategies are deviated with the planned scheme. Compared with existing techniques, the proposed method gives a better yield. The IEEE 14 bus system of power loss correlation with various techniques is shown in Table 6 . This technique for power loss is compared with our proposed method, as shown in Figure12. When a fault is connected in the second bus, GSA-Bat algorithm, FA-CS and ALO-IWOA are the special strategies. Control misfortune in IEEE 14 bus system is immensely reduced to $8.12 \mathrm{MW}$ by applying the proposed method and different processes are compared.

Table 6. Power loss at the single generator problem.

\begin{tabular}{cccccccc}
\hline \multirow{2}{*}{$\begin{array}{c}\text { Fault } \\
\text { generator }\end{array}$} & \multicolumn{2}{c}{ Best position } & \multicolumn{5}{c}{ Power loss in MV } \\
\cline { 2 - 7 } & From & To bus & Normal & Fault & GSA-BAT & FA-CS & Proposed \\
& bus & & & & & & \\
\hline 2 & 3 & 5 & 12.36 & 14.42 & 11.22 & 10.56 & 9.12 \\
\hline
\end{tabular}

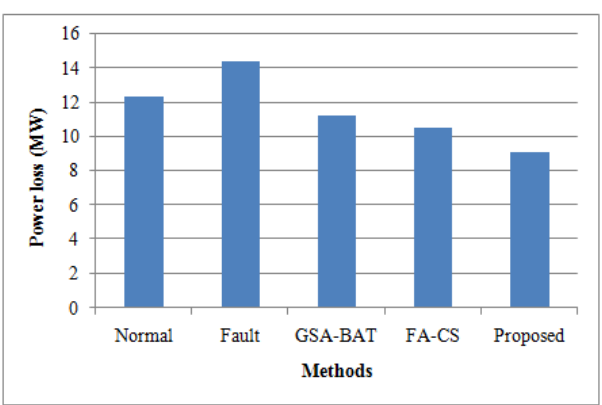

Figure 12. Power loss comparison with single generator fault.

\section{(iii) Test system 3: IEEE 57 bus system}

By applying load fault conditions, the power system dynamic stability was analysed using the proposed strategy in an IEEE 57 transport test framework. 7 generator transport, 50 load transport and 80 transmission lines are comprised by the transport framework (Bhattacharya and Chattopadhyay, 2010). System stability was analysed with load bus contingencies. In every incident, the quantity of overloaded lines (OLL) and the number of voltage limit violation buses (VLVB) were found. The performance index (PI) was calculated using the summation of a total number of OLL and VLVB at a specific time. As per the PI value, critical buses were ranked and other bus values were set at zero. Voltage deviation (p.u) for bus voltage limit was used as the criterion for identifying buses which included the voltage limit violations; lines were loaded to their thermal limits, with $100 \%$ loading regarded as the criterion for identifying overloaded lines; and the range (0.9-1.1). Hence, 15 possible contingencies were created and their corresponding stability performances were analysed.

Table 7. Contingency ranking of buses for IEEE 57 bus systems.

\begin{tabular}{lllll}
\hline Contingency bus no. & OLL & VLVB & PI & Rank \\
\hline 31 & 5 & 6 & 11 & 1 \\
42 & 4 & 4 & 8 & 2 \\
38 & 34 & 4 & 7 & 3 \\
13 & 4 & 3 & 7 & 4 \\
47 & 3 & 4 & 7 & 5 \\
44 & 3 & 3 & 6 & 6 \\
29 & 2 & 4 & 6 & 7 \\
27 & 2 & 3 & 5 & 8 \\
23 & 2 & 3 & 5 & 9 \\
20 & 3 & 2 & 5 & 10 \\
41 & 1 & 3 & 4 & 11 \\
54 & 2 & 1 & 3 & 12 \\
52 & 1 & 2 & 3 & 13 \\
28 & 1 & 2 & 3 & 14 \\
10 & 2 & 1 & 3 & 15 \\
\hline
\end{tabular}


Table 8. Voltage violation and power loss for IEEE 57 bus systems.

\begin{tabular}{|c|c|c|c|c|c|c|c|c|c|c|}
\hline \multirow{4}{*}{$\begin{array}{l}\text { Bus } \\
\text { no. }\end{array}$} & \multicolumn{2}{|c|}{ Before using UPFC } & \multicolumn{8}{|c|}{ After using UPFC with the proposed method } \\
\hline & \multirow{3}{*}{$\begin{array}{c}\text { Buses with } \\
\text { voltage } \\
\text { violation }\end{array}$} & \multirow{3}{*}{$\begin{array}{c}\text { Power } \\
\text { loss } \\
\text { (MW) }\end{array}$} & \multicolumn{2}{|c|}{$\begin{array}{l}\text { Optimal } \\
\text { location }\end{array}$} & \multirow{3}{*}{ VLVB } & \multicolumn{4}{|c|}{ UPFC capacity } & \multirow{3}{*}{$\begin{array}{c}\text { Power } \\
\text { loss } \\
\text { (MW) }\end{array}$} \\
\hline & & & \multirow{2}{*}{$\begin{array}{l}\text { From } \\
\text { bus }\end{array}$} & \multirow{2}{*}{$\begin{array}{l}\text { To } \\
\text { bus }\end{array}$} & & \multicolumn{2}{|c|}{ From bus } & \multicolumn{2}{|c|}{ To bus } & \\
\hline & & & & & & $\mathrm{P}$ & $\mathrm{Q}$ & $\mathrm{P}$ & $\mathrm{Q}$ & \\
\hline 31 & 30,32 & 27.4869 & 29 & 52 & - & 11.49 & 5.85719 & 72.8131 & 6.25114 & 21.6910 \\
\hline 42 & $30,33,35$, & 27.3911 & 57 & 56 & - & 7.467 & 16.6905 & 2.5485 & 7.3565 & 25.3597 \\
\hline 38 & 30,33 , & 27.6015 & 6 & 8 & - & 23.92 & 3.79723 & 30.2034 & 3.2269 & 21.3123 \\
\hline 13 & $30,35,36$ & 27.5793 & 49 & 50 & - & 8.207 & 7.3742 & 1.8537 & 0.59822 & 25.8452 \\
\hline 47 & $30,33,35$ & 28.0832 & 37 & 38 & - & 29.72 & 61.6961 & 56.0539 & 45.6702 & 20.4791 \\
\hline 44 & $30,35,36$ & 27.4658 & 6 & 8 & - & 36.26 & 14.8034 & 3.7817 & 2.2707 & 22.9691 \\
\hline 29 & $29,30,35,5$ & 27.4647 & 8 & 9 & - & 1.699 & 25.7588 & 16.3663 & 48.9781 & 26.2586 \\
\hline 27 & $30,35,36$ & 27.4109 & 52 & 53 & - & 6.286 & 23.5514 & 1.5135 & 5.6852 & 26.0278 \\
\hline 23 & $30,35,36$ & 27.3173 & 23 & 24 & - & 13.78 & 1.65653 & 28.3989 & 0.42491 & 22.7433 \\
\hline 20 & 30,35 & 27.1516 & 8 & 9 & - & 30.30 & 30.5996 & 24.2265 & 5.6469 & 23.9139 \\
\hline 41 & $30,35,36$ & 27.2497 & 57 & 56 & - & 2.148 & 13.4071 & 1.1221 & 6.386 & 26.2710 \\
\hline 54 & 53 & 27.2228 & 53 & 54 & - & 1.240 & 1.196 & 10.5456 & 0.102443 & 25.9005 \\
\hline 52 & 30,53 & 27.2629 & 52 & 53 & - & 6.750 & 24.4026 & 13.802 & 25.5326 & 25.5301 \\
\hline 28 & 30,35 & 27.1946 & 6 & 7 & - & 11.98 & 5.38479 & 43.5565 & 4.64815 & 23.2399 \\
\hline 10 & 10 & 27.2144 & 50 & 51 & - & 20.15 & 17.3833 & 8.4545 & 6.7668 & 23.8811 \\
\hline
\end{tabular}

Table 9. UPFC installation cost comparison.

\begin{tabular}{cc}
\hline Solution techniques & UPFC installation cost (\$/KVAR) \\
\hline FA & 186.0153 \\
\hline Artificial bee colony-Artificial neural & 184.4326 \\
network (Karthikeyan and Ajay-D- & 183.2269 \\
\hline CS-FA & 181.3362 \\
\hline
\end{tabular}

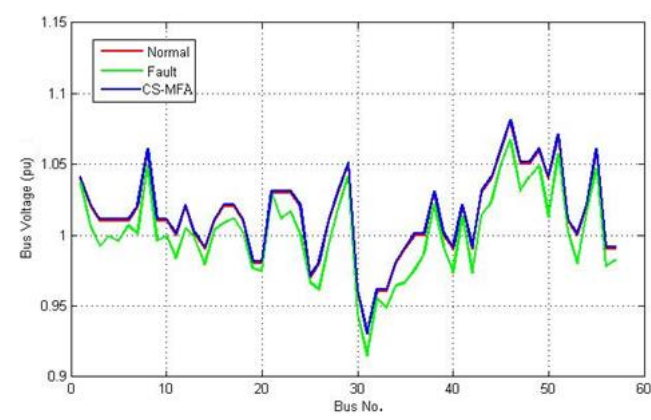

Figure 13. During the contingency voltage profile at transport number 20 .

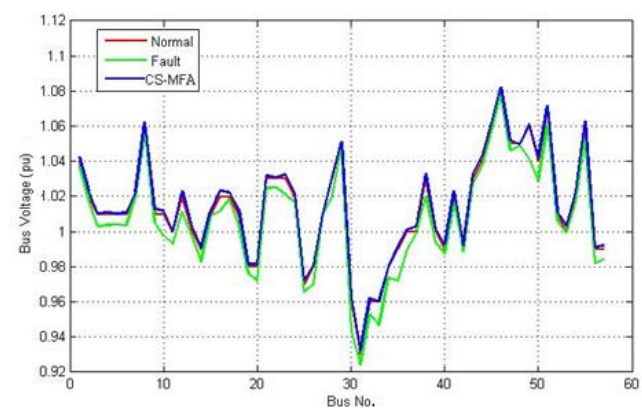

Figure 14. During the contingency voltage profile at transport number 29.

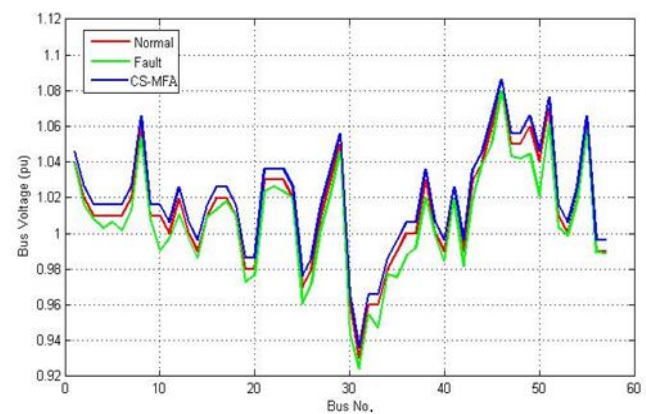

Figure 15. During the contingency voltage profile at transport number 50 .

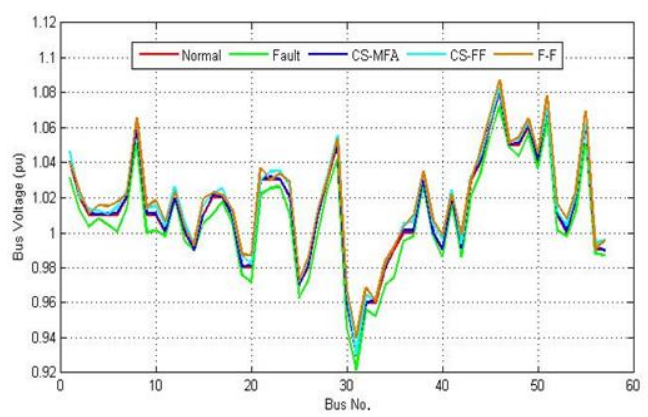

Figure 16. Bus voltage profile comparison.

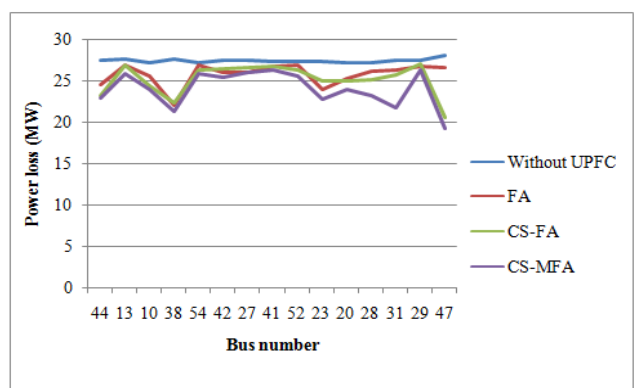

Figure 17. Power loss comparison. 


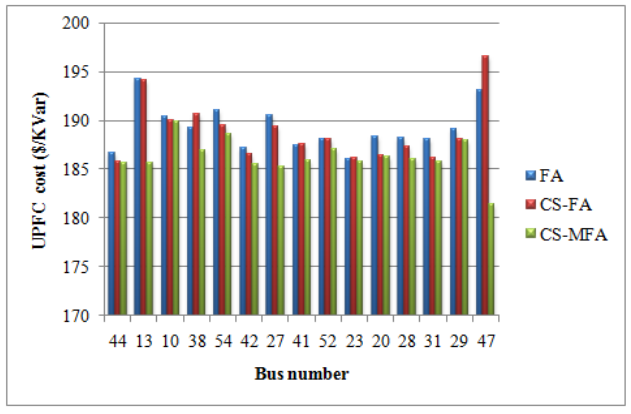

Figure 18. UPFCs cost comparison.

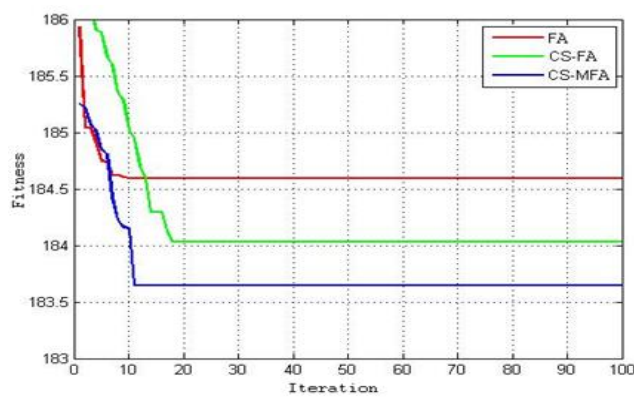

Figure 19. Convergence characteristics comparison.

Different types of contingency were randomly created in the load buses and the corresponding OLL, VLVB and PI, and their ranking are described in Table 7. Based on this ranking, the priority of the critical buses is determined. The test system parameters are analysed in both the fault conditions and after using UPFCs, as described in Table 8. This shows the optimal location of a UPFC during the fault time and the corresponding UPFC capacity. By using the optimal parameters, both power loss and voltage violation were reduced. The UPFC installation cost comparison which was analysed using different techniques is shown in Table 9. Figures 13, 14 and 15 explain the voltage profile of the buses during the load bus faces the contingency. The three different voltage profiles are the typical condition, flaw condition and proposed strategy. Initially, the normal condition has a voltage profile that does not ignore the stability limit. Once a fault occurs, the bus present in the system deviates from the normal value. Using the proposed method, the fault condition is resolved by locating the UPFCs in the ideal area with the ideal parameters. Figure 16 shows that the bus voltage profile is then compared with the proposed method and existing techniques such as the FA and CS-FA. From this figure, it can be seen that, when compared with other techniques, the proposed method minimises voltage deviation more effectively. When contrasted with existing techniques, the power loss of the proposed technique is shown in Figure 17. The power loss of the system in fault conditions without a UPFC is 27.1946 MW. By using the FA technique with a UPFC, it is $23.9709 \mathrm{MW}$ and hybrid CS-FA has a power loss of 20.4719 MW. Due to its robust construction and global searching ability, power loss in the framework is greatly reduced to 19.2446 MW using the proposed technique. In Figure 18, the proposed method reduces the expense of the UPFC to 188.3362 \$/KVAR and UPFC costs are compared using various techniques. Figure 19 shows the convergence characteristics of the proposed strategy matched with different techniques.

\section{Conclusion and Future Scope}

The UPFC is demonstrated for enhancing the dynamic stability of the system in this thesis. ALO and IWO are considered effective techniques. This method can identify optimal locations and settings for UPFCs in electric power systems. By using the MATLAB/Simulink stage, the proposed method is executed. Initially, normal behaviour in the system is examined. Thereafter, the over-burdening problem is produced, and the voltage profile and power loss of the system are assessed. The maximum power loss line is identified during over-burdening conditions for setting the UPFCs devices, assisted by the ALO algorithm. In the case of UPFCs distribution, the UPFCs optimal location and sizing units are sought. The outcomes demonstrate that, with UPFCs, the proposed method reduces voltage deviation estimations, over-burden problems and costs more effectively than both PSO and ALO. The proposed technique can therefore be considered an efficient solution for handling distribution issues. Discoveries also confirm the effectiveness of UPFCs in easing the resulting overburdening within power systems. In the future, different objectives for the location, capacity, techniques and types of FACTS devices can all be used to resolve problems in the power flow.

\section{Notes on Contributors}

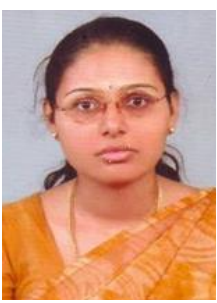

Dr Mythili Shanmugam obtained her bachelor's degree in Electronics from Bharadidasan University, Tirchirapalli in 1993. Then she obtained her master's degree in Power Electronics in 1999 and Ph.D. in Power Electronics majoring in Motor Control. She is Principal of Mahendra Engineering College for Women. Her current research interests are induction motor drives, power electronics and signal processing applications.

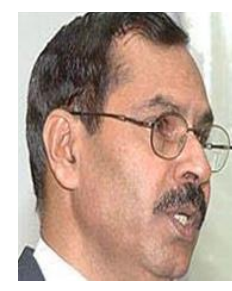

Dr K Thiyagarajah received his B.Eng. in 1976, M.Eng. in 1979, and Ph.D. degree in 1998 from The University of Madras and Indian Institute of Science. $\mathrm{He}$ is the Chief Executive Officer of KSR Educational Institutions, Tamil Nadu, India. His research interests include power electronics, alternative current motor drives and communications. 


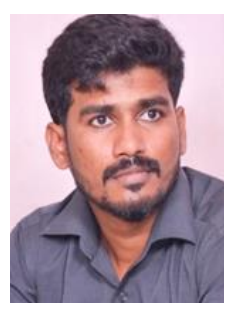

Mr Paulthurai Rajesh received his Bachelor of Engineering and Master of Engineering in Electrical and Electronics Engineering from Anna University, Chennai, India. He has more than seven years of IT experience. His current research interests include artificial intelligence, power system, smart grid technologies and soft computing.

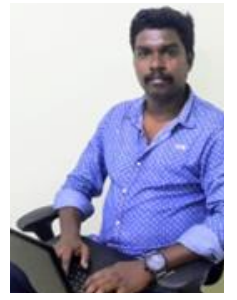

Mr Francis H Shajin received his Bachelor of Engineering and Master of Engineering in Electronics and Communication Engineering from Anna University, Chennai, India. He has more than seven years of IT experience. His current research interests include everylarge-scale integration, soft computing, image processing, machine learning and networking.

\section{References}

[1] Abd-Elazim S and Ali E (2016a). Imperialist competitive algorithm for optimal STATCOM design in a multimachine power system. International Journal of Electrical Power \& Energy Systems, 76, pp. 136-146.

[2] Abd-Elazim S and Ali E (2016b). Optimal SSSC design for damping power systems oscillations via Gravitational Search Algorithm. International Journal of Electrical Power \& Energy Systems, 82, pp. 161168.

[3] Ali E and Abd-Elazim S (2012). Coordinated design of PSSs and TCSC via bacterial swarm optimization algorithm in a multimachine power system. International Journal of Electrical Power \&Energy Systems, 36, pp. 84-92.

[4] Ali E, Abd-Elazim S and Abdelaziz A (2017). Antlion optimization algorithm for optimal location and sizing of renewable distributed generations. Renewable Energy, 101, pp. 1311-1324.

[5] Ali E, Abd-Elazim S and Abdelaziz A (2016). Antlion optimization algorithm for renewable distributed generations. Energy, 116, pp. 445-458.

[6] Bathina V and Gundavarapu V (2014). Optimal location of thyristor-controlled series capacitor to enhance power transfer capability using firefly algorithm. Electric Power Components and Systems, 42, pp. 1541-1553.

[7] Bhattacharya A and Chattopadbyay P (2010). Solution of optimal reactive power flow using biogeographybased optimization. International Scholarly and Scientific Research \& Innovation, 4(3), pp. 26-34.

[8] Cao G, Chen L and Aihara K (2015). Power system voltage stability assessment based on branch active powers. IEEE Transactions on Power Systems, 30, pp. 989-996.
[9] Cao G and Hill D (2010). Power system voltage small-disturbance stability studies based on the power flow equation. IET Generation, Transmission \& Distribution, 4, pp. 873-882.

[10] Chitra S and Devarajan N (2014). Circuit theory approach for voltage stability assessment of reconfigured power network. IET Circuits, Devices \& Systems, 8, pp. 435-441.

[11] Colak I, Sagiroglu S, Fulli G, Yesilbudak M and Covrig C (2016). A survey on the critical issues in smart grid technologies. Renewable and Sustainable Energy Reviews, 54, pp. 396-405.

[12] Deepa SN and Rizwana JB (2015). Imperialist competitive algorithm for minimization of losses by optimally locating FACTS controllers in power system. IU-Journal of Electrical \& Electronics Engineering, 15, pp. 1889-1896.

[13] Ganguly S (2014). Impact of unified power-quality conditioner allocation on line loading, losses, and voltage stability of radial distribution systems. IEEE Transactions on Power Delivery, 29, pp. 1859-1867.

[14] Hassan L, Moghavvemi M, Almurib H and Steinmayer O (2013). Application of genetic algorithm in optimization of unified power flow controller parameters and its location in the power system network. International Journal of Electrical Power \& Energy Systems, 46, pp. 89-97.

[15] Jordehi A (2015). Particle swarm optimisation (PSO) for allocation of FACTS devices in electric transmission systems: A review. Renewable and Sustainable Energy Reviews, 52, pp. 1260-1267.

[16] Karthikeyan M and Raj PA (2014). Artificial bee colony $(\mathrm{ABC})$ and neural network based OPF technique with FACTS controller. Journal of Theoretical \& Applied Information Technology, 62(2), pp. 524-538.

[17] Kavitha K and Neela R (2017). Optimal allocation of multi-type FACTS devices and its effect in enhancing system security using BBO, WIPSO \&PSO. Journal of Electrical Systems and Information Technology. [online]. 5(3), pp. 777-793. Available at: <https://doi. org/10.1016/j.jesit.2017.01.008>. [Accessed on 12 December 2018].

[18] Khodabakhshian A, Esmaili M and Bornapour M (2016). Optimal coordinated design of UPFC and PSS for improving power system performance by using multi-objective water cycle algorithm. International Journal of Electrical Power \& Energy Systems, 83, pp. 124-133.

[19] Kumar B and Srikanth N (2017).A hybrid approach for optimal location and capacity of UPFC to improve the dynamic stability of the power system. Applied Soft Computing, 52, pp. 974-986. 
[20] Manoranjitham GE and Shunmugalatha A (2015). RETRACTED: Application of firefly algorithm on optimal power flow control incorporating simplified impedance UPFC Model. International Journal of Electrical Power \& Energy Systems, 71, pp. 358-363.

[21] Mehrjerdi H and Ghorbani A (2017). Adaptive algorithm for transmission line protection in the presence of UPFC. International. Journal of Electrical Power \& Energy Systems, 91, pp. 10-19.

[22] Mohanty A, Viswavandya M and Mohanty S (2016). An optimised FOPID controller for dynamic voltage stability and reactive power management in a standalone micro grid. International Journal of Electrical Power \& Energy Systems, 78, pp. 524-536.

[23] Mok T, Liu H, Ni Y, Wu F and Hui R (2005). Tuning the fuzzy damping controller for UPFC through genetic algorithm with comparison to the gradient descent training. International Journal of Electrical Power \& Energy Systems, 27, pp. 275-283.

[24] Motiebirjandi A and Fateh D (2017). Optimal placement method of multi UPFCs to damp power system oscillations. International Transactions on Electrical Energy Systems, 27, pp. 1-13.

[25] Murali D, Rajaram M and Reka N (2010). Comparison of FACTS devices for power system stability enhancement. International Journal of Computer Applications, 8(4), pp. 30-35.

[26] Nagib M, Othman M, Naiem A and Hegazy Y (2017). Integrating tidal energy to solve dynamic economic load dispatch problem using IWO. In: 2017 IEEE International Conference on Environment and Electrical Engineering and 2017 IEEE Industrial and Commercial Power Systems Europe (EEEIC / I\&CPS Europe). Milan: IEEE, pp. 1-6.

[27] Packiasudha M, Suja S and Jerome J (2017). A new cumulative gravitational search algorithm for optimal placement of FACT device to minimize system loss in the deregulated electrical power environment. International Journal of Electrical Power \& Energy Systems, 84, pp. 34-46.

[28] Pahlavani $\mathrm{M}$ and Mohammadpour H (2011). Damping of sub-synchronous resonance and lowfrequency power oscillation in a series-compensated transmission line using gate-controlled series capacitor. Electric Power Systems Research, 81, pp. 308-317.

[29] Palukuru N, Dey SH, Datta T and Paul S (2014). Voltage stability assessment of a power system incorporating FACTS controllers using unique network equivalent. Ain Shams Engineering Journal, 5, pp. 103-111.

[30] Pradhan P, Sahu R and Panda S (2016). Firefly algorithm optimized fuzzy PID controller for AGC of multi-area multi-source power systems with UPFC and SMES. Engineering Science and Technology, an International Journal, 19, pp. 338-354.
[31] Reddy PD, Reddy VV, Manohar TG (2017). Antlion optimization algorithm for optimal sizing of renewable energy resources for loss reduction in distribution systems. Journal of Electrical Systems and Information Technology, 28, pp. 669-678.

[32] Sahu R, Gorripotu T and Panda S (2015). A hybrid DE-PS algorithm for load frequency control under deregulated power system with UPFC and RFB. Ain Shams Engineering Journal, 6, pp. 893-911.

[33] Shayeghi H, Shayanfar H, Jalilzadeh S and Safari A (2010). Tuning of damping controller for UPFC using quantum particle swarm optimizer. Energy Conversion and Management, 51, pp. 2299-2306.

[34] Shrawane S, Diagavane M and Bawane N (2015). Optimal reactive power dispatch by furnishing UPFC using multi-objective hybrid GAPSO approach for transmission loss minimisation and voltage stability. In: 2015 International Conference on Nascent Technologies in the Engineering Field (ICNTE). India: IEEE, pp. 1-6.

[35] Velmurugan T, Khara S, Nandakumar S and Saravanan B (2016). Seamless vertical handoff using invasive weed optimization (IWO) algorithm for heterogeneous wireless networks. Ain Shams Engineering Journal, 7, pp. 101-111.

[36] Vijay Kumar B and Srikanth N (2015a). Optimal location and sizing of unified power flow controller (UPFC) to improve dynamic stability: A hybrid technique. International Journal of Electrical Power \& Energy Systems, 64, pp. 429-438.

[37] Vijay Kumar B and Srikanth N (2015b). Dynamic stability of power systems using UPFC: Bat-inspired search and gravitational search algorithms. Asian Journal of Control, 18(2), pp. 733-746.

[38] Vijay Kumar B and Srikanth N (2016). Bat algorithm and firefly algorithm for improving dynamic stability of power systems using UPFC. International Journal on Electrical Engineering and Informatics, 8, pp. 164188.

[39] Xu Y and Li F (2014). Adaptive PI control of STATCOM for voltage regulation. IEEE Transactions on Power Delivery, 29, pp.1002-1011.

[40] Yahyatabar A and Najafi A (2017). A quadratic reproduction based invasive weed optimization algorithm to minimize periodic preventive maintenance cost for series-parallel systems. Computers \& Industrial Engineering, 110, pp. 436461.

[41] Yoo C, Kim S, Jung J and Ko S (2017). Highdimensional feature extraction using bit-plane decomposition of local binary patterns for robust face recognition. Journal of Visual Communication and Image Representation, 45, pp.11-19. 